\title{
Empowering to disempower: a dilemma when working with adults with learning difficulties
}

\author{
By Beccy Blow (Goldsmiths, University of London)
}

Is the use of participatory techniques effective in empowering and engaging adults with learning difficulties within their 'communities'? Despite the progress that has been made to introduce structures for consultation, it is not clear to what extent people are participating. Participation appears to be driven by a Government agenda that is more about achieving consultation forums and less about listening to what is being said or making efforts towards inclusive practice. Who ultimately benefits from empowering practices? This paper discusses the complex ethical considerations of adopting participatory processes with adults with learning difficulties. The potential for individuals to contribute in participatory processes often rests on their ability to communicate verbally within consultative structures and ultimately depends on a degree of interpretation. The challenge for the researcher is to create a meaningful participatory dialogue with research participants whilst facing the difficulties associated with claiming that messages have been clearly understood. This paper draws parallels between the ways in which power relations are analysed in both contemporary learning difficulty discourse and participatory practice and discourse in development work. I also reflect on the use of labelling in the context of learning difficulty and the ways in which labels can be used as a form of control. Participatory techniques can, without significant adjustment and adaptation, result in reinforcing a lack of power. The language of empowerment disguises institutional forms of discrimination that continue to exclude people with learning difficulties from participating as equal citizens.

\section{Introduction: the 'community care' approach}

The move towards a 'community care' approach in social policy during the 1990s in the United Kingdom has been viewed as an unsuccessful mechanism for community engagement and participation (Concannon 2005, Roberts 1997, Rooney 2002). The influence of 'normalisation' and 'ordinary life' principles were instrumental in driving forward the transition of care for adults with learning difficulties from models of institutional services to a focus on a model of community care. This new model challenged both the limited notion of 'capacity' for adults with learning disabilities and assumptions about the autonomy they could 'have' or 'be given'. Despite these forward-thinking aims, Roberts (1997:156) claims 'evidence suggests that the new community care system has contributed little, if at all, to empowering people with learning disabilities in their everyday lives'. Why have attempts at empowerment failed to benefit adults with learning difficulties? It seems to me that there has been more progress in the development of research techniques related to similar questions within participatory research in development work. In this article I will therefore discuss the relationship between participatory discourse in social policy and development work and draw on various texts from both disciplines in order to 
examine the ways in which minority voices, in particular those with communication difficulties, are being heard.

In this article I refer to my own research project, which examined the friendship networks of people with learning disabilities. This small project was carried out with adults and teenagers with learning disabilities in a day centre funded through the county council. The day centre provides activities, social engagements, learning opportunities and employment options for adults with learning difficulties. At the time of my research, a 'drop-in service' for teenagers with mild to moderate learning difficulties was meeting on Saturday mornings and providing a space for young people aged 16-25 to meet, socialise, and provide access to employment opportunities advice and guidance. And finally a voluntary service called a Gateway Club for adults (age range 18-60 years) ran once a week in the evenings, providing a varied programme of activities including arts, music, and sports. All these settings would fit within the umbrella of community care services targeting people with learning difficulties who live within the West Sussex area, in the UK.

\section{Research methods: exploring friendships}

I conducted a series of individual discussions at the day centre, assisting clients at the centre in drawing style diagrams (see Figure 1) where people were represented by circles connected to the person at the centre.

Figure 1. Example of network / linkage diagram (also known as chapatti diagrams)

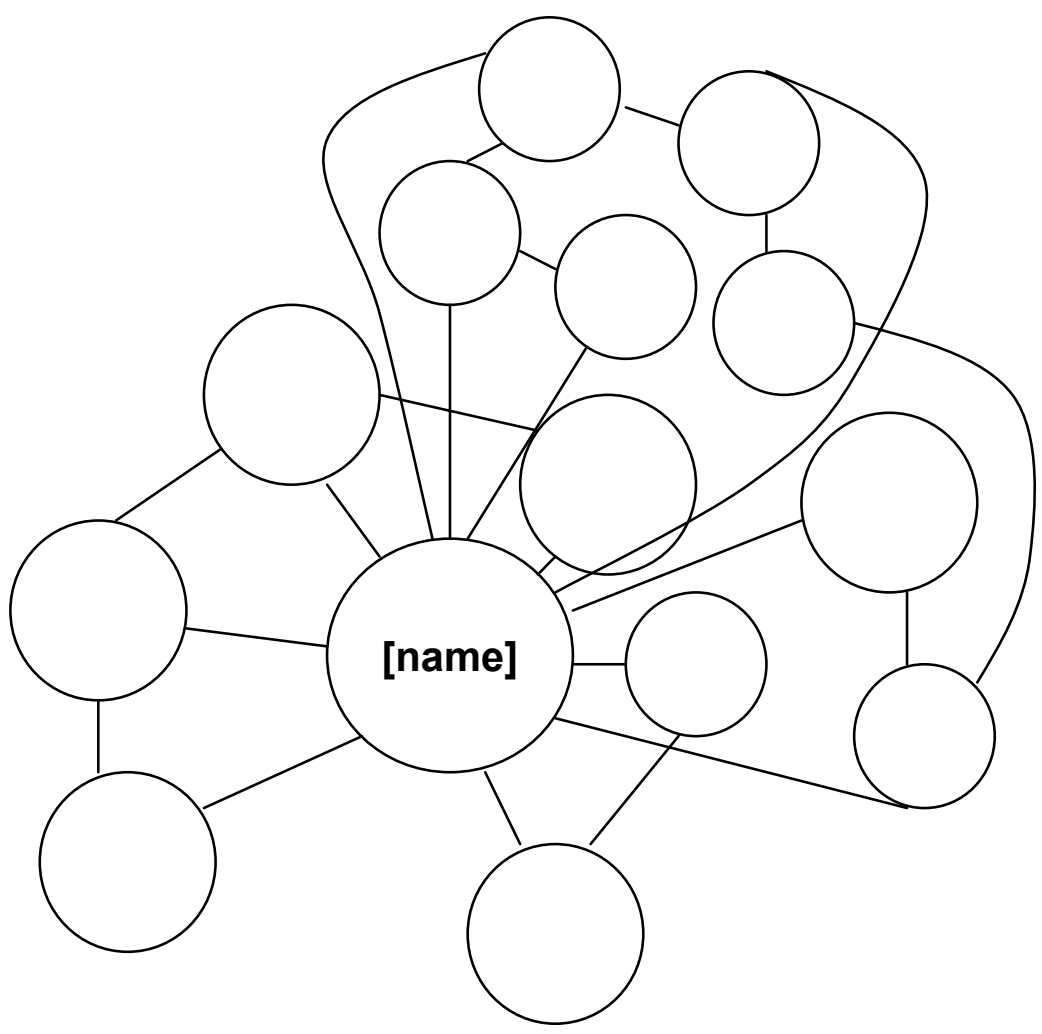


The circles nearest the centre were closer friends and the smaller circles were friends on the periphery. Lines connect people who know each other. The clients selected for me by the day centre provided a range of results based on their ability to speak. This included one client who in effect spoke through an interpreter (see the section below entitled 'One version of the truth'). The clients responded well to the opportunity to have a chat with me, but it was not always easy to ascertain whether they understood the idea of my research project. At the teenage drop-in I conducted an informal covert style of research by introducing myself to the attendees and chatting with them. I did ask them to try out some drawings of friendship diagrams. There was a high level of response to our discussions and some of the young people were very open and eloquent when discussing their friendships. My role at the Gateway Club was somewhat different, as there I was in the position of Club Leader-a position I had been in from before my research project started. My research was based on diary notes from the evenings which I spent at the Club talking to the members, asking questions, and also engaging in more in-depth discussions with the adult volunteers, the majority of whom had children with learning difficulties.

I wanted to explore the ways in which people with learning difficulties were able to establish and sustain relationships. My belief was that individuals with learning difficulties have very limited choice and control over their close relationships. This was based on several assumptions. Firstly, that people with caring responsibilities often become a central part of a small and limited friendship network of those individuals with learning difficulty, resulting in a blurring of the boundaries between friends and those employed to work with those persons. Secondly, based on my limited experience at the Gateway Club, I noticed that there were frequent upsets, quarrels and 'fallings out' with members at the club. I felt that this may be due to those persons having limited choice about whom they spend their social time with, as there were few specialist services available to them. Consequently, a lot of time was spent with people who were not necessarily chosen as friends. Thirdly, the process of friendship was at times subject to a process of intervention by families seeking to facilitate the forming, sustaining, and occasionally severing of relationships.

Any examples used from this research study are for illustrative purposes only. I owe a great deal to the support of the voluntary and statutory services that allowed me to carry out my research within their institution, and especially to those whom I spent time with in discussions. My interest in this topic was spurred from my position in the Gateway Club, the observations and interactions with the members at the Club and more broadly from my background in youth and community work. As a youth worker for the past five years I realised how little I knew about issues faced by individuals with learning difficulties, particularly in the development of social skills and social networks. A key finding from my research indicated that the systems and constraints on social development, including relationships, increase with age. Age also tended to be an indication of the level of institutionalisation faced by individuals, which greatly affected their relationships. I hoped that knowing more about these processes would enable me to provide better support to teenagers with learning difficulties when facing challenges forming relationships, and would also help me to support the adults I had built relationships with at the Gateway Club. 


\title{
Definitions
}

'Learning difficulty' is synonymous with the term 'learning disability'. A description from the Mencap Organisation provides a helpful description of the impact of learning disability on people's lives:

\begin{abstract}
A learning disability affects the way someone learns, communicates or does some everyday things. Some [have] a learning disability all through their life. There are many different types of learning disability. They can be mild, moderate or severe. Some people with a mild learning disability do not need a lot of support in their lives. But other people may need support with all sorts of things, like getting dressed, going shopping, or filling out forms. Some people with a learning disability also have a physical disability. This can mean they need a lot of support 24 hours a day. This is known as profound and multiple learning disability (PMLD). A learning disability does not stop someone from learning and achieving a lot in life, if they get the right support. A learning disability can affect someone's life a lot. This is partly because people with a learning disability may find it harder to understand things than other people. But it is also because other people often do not understand what it means for someone to have a learning disability. As a result people with a learning disability often do not get treated properly. (URL 1)
\end{abstract}

Symptoms such as illiteracy, lack of speech and occasionally poor long-term memory can affect the level of participation of someone with a learning difficulty both within their community and also in decision-making situations. Conditions often associated with learning disability are cerebral palsy, epilepsy, autism and Aspergers syndrome, and the two most common causes of inherited learning disability are Fragile $\mathrm{X}$ syndrome and Down's syndrome (URL 2). I was soon to learn in my own research that these symptoms can create significant barriers to communication-particularly in relation to my own methods of communicating, which I was going to have to alter in order to engage and enable people to take part as possible 'informants'.

\section{A lesson learnt the hard way}

Having done a reasonable amount of reading around participatory techniques that had been used with people with learning difficulties, particularly in helping to create oral life histories (Gray and Ridden 1999), I decided that creating diagrams and drawings was the best method to use. In using drawing techniques I was trying to avoid overreliance on literacy and concentration. In the majority of cases my informants could write, though in one case - the case that I wish to briefly highlight here-the participant could write their own name but not spell other people's names. At times I wrote the name down and the participant would copy it. It had not occurred to me that the participant might not be able to read the word once it was written down. In effect, I had helped to create a drawing which the participant could not understand. I was disappointed in my lack of awareness of the literacy skills of this individual and feel I fell into the trap of reproducing an experience of disablement for that person (Moore et al. 1998). On this occasion it would have been necessary to assess the informant's literacy in advance of the research and therefore introduce other ways of constructing the drawing, using symbols or even photographs. Unfortunately I did not build in time to try any different methods and so was left with a feeling that I had failed that particular person. I was to learn very quickly that there is no one clear method to achieve participation for people with learning difficulties, which in hindsight makes 
complete sense. As levels of ability differ from person to person, so must the ways in which research is adapted to meet individuals' needs. Thomforde (1998:127) in his analysis of the use of participatory techniques with people with disabilities also noted that illiteracy was a problem when using ranking activities as the problems being addressed 'did not lend themselves well to written symbols'.

\section{Hearing silent voices}

There is widespread agreement that working with people with learning difficulties presents significant communication challenges (Concannon 2005, Grant 1997, Rooney 2002, Stevenson and Parsloe 1993, Walmsley and Johnson 2005). Arguably, the most difficult obstacle to overcome is how to communicate with individuals who have little or no verbal communication. This issue is demonstrated by data from the Foundation for People with Learning Disabilities, used by Concannon (2005) to show firstly that $80 \%$ of people with severe learning difficulties fail to acquire effective speech. He then states that ' $20 \%$ have no verbal communication skills but do demonstrate intentional communication', whilst ' $20 \%$ have no intentional communication skills' (ibid:103). Set within the context of participation and engagement, Concannon notes that 'the government has a policy of communication and involvement, but at least $20 \%$ of people with learning disabilities are known not to have a means of communication interaction' (ibid:103).

Processes for engaging are undeniably reliant on some form of known or shared communication structure, and without this individuals are excluded. If there is no practical way of understanding other people, then participation as a mechanism for involving, engaging and empowering, is redundant. Rooney (2002:155) presents a similar argument: 'it is difficult to be part of a community if you are unable to communicate and interact. Communication is the precursor to social activity.' Would society exist without communication? For those individuals who do have some form of intentional communication, barriers still crop up. Indeed, Cogher (2005:263) points out that a range of complex communication difficulties makes 'effective communication one of the more vulnerable areas of their lives'. Cogher presents a model of communication skills divided into inputs, language processing, and language output. In communicating with an adult with learning difficulties, there are several practical limitations. How do we know we have understood the 'input' from that person? How do we know that that person has accepted our interpretation of what was communicated? How do we know we have been understood, in other words, that our language processing and language output is correct? Cogher distinguishes two aspects of language processing: 'understanding of language' and 'expression of language'. For adults with learning difficulties, they are likely to have underdeveloped language processing skills. In the simplest terms, are we communicating in the same 'language'? The answer is: probably not.

In these cases, participation relies on the skills, expertise and dedication of families, carers and researchers. Even in cases where people have no speech (which occurred during my research), there are different techniques for communicating involving technology such as message boards. Research shows that methods of communicating need to be adapted, listening skills have to be more finely tuned to an individual, and use of such tools as symbols, sounds and body movement may be necessary. All this takes time and in cases where there are more complex communication difficulties, the right amount of time is usually not available due to budget constraints or high 
workload (Concannon 2005). Whatever the process, there is an inevitable reliance on interpretation. This means that our interpretation is the closest to understanding that we can achieve through known methods.

\section{One version of the truth?}

In the implementation of consultation and involvement where there is a language or communication difficulty, a support worker or family member takes responsibility for interpreting what an individual wants or needs (Cogher 2005). This has developed into the various forms of advocacy available to people with learning difficulties, but ultimately relies on a shared understanding between two people. Advocacy is a system that provides a representative for an individual in challenging situations, such as negotiating with social services. Concannon underlines the dilemmas where an advocate is involved:

Communication is a two-way process but one where reception may be as difficult as expression. If an advocate is included, having another person involved in the process is in itself filled with potential challenges. It is not only understanding what is said that is the problem, but also the hinterland that lies behind it. (Concannon 2005:104, original emphasis)

Whilst the need for someone working alongside an adult with learning difficulty is accepted as an effective mechanism of support, especially for those who live independently, there is also acknowledgement that this process is subject to infinite exploitation (Brandon et al. 1995). Advocates have a responsibility to 'translate and interpret words and feelings of the person to others as well as backing their partner directly' (ibid:9). In this process of translation, how is it possible to ensure that the needs of adults with learning difficulties have been understood? And, if wishes and desires have been understood, have they been acted upon? For those people with verbal and/or intentional communication it may be possible to show satisfaction or dissatisfaction with decisions and changes that have been made. However, the reactions likely to arise are again subject to existing power relations, where previous experiences tend to be dominated by having little or no influence in decision-making. For individuals in a powerless position, developing a voice for participation will involve taking power or at least forming partnerships (ibid). This is a reminder of the fragile nature of the process of empowerment.

At the day centre I interviewed a young man who had cerebral palsy and was unable to speak. He had the use of a communication board but seemed happier talking 'through' his support worker. This person interpreted sounds, eye movements and body postures in order to tell me the answer to the questions that I had asked the young man. He was able to understand verbal communication but not able to respond using verbal language. The support worker appeared confident with the way that understanding had developed between them and translated his answers to me. Occasionally answers would be given on his behalf (without apparently communicating with him), presumably based on experience of working with him and his family. His support worker described the significant relationships in his life and one particularly long-lasting friendship since he was a boy. She also told me of the ways in which his mother arranged for him to keep in contact with people and was very keen on him spending a lot of time with other people his age. The worker and the client had obviously developed a unique way of understanding each other. But how did I know this? It did occur to me that I had no way of knowing if the support worker 
was taking over. Undoubtedly she was providing an 'interpretation' of what she felt was being said, as without the ability to communicate with him it was impossible to ratify his responses. Grant (1997:129) claims that each person has their own unique way of getting their message across, and our challenge as professionals is to develop 'techniques and technologies to help people express their needs and views'.

The role of the researcher as advocate can lead to a blurring of boundaries in the research relationship (Stalker 1998, Walmsley and Johnson 2003). Walmsley and Johnson (2003) view the cross-over into the role of advocate as an unavoidable consequence of inclusive research. Stalker (1998:17) also recognises this tension and urges that a "balance needs to be struck which ensures that the researcher neither intrudes unwanted in peoples" lives, nor becomes so immersed in "the cause" that she loses sight of the academic agenda'. In encouraging people with learning difficulties to become more engaged in the research process, there are opportunities for their views and opinions to be heard-particularly those who may experience the most marginalisation. Concannon (2005) highlights the concern in relation to advocacy that there is no real power over decision-making, and he cites cases where professionals acting as advocates are expected to signpost to statutory services, rather than help people raise a dispute. It is evident why some have argued that within this context there is a 'rhetoric' of participation discourse (Roberts 1997), rather than a tangible way forward for participation in the 'building of the community as equal citizens' (Concannon 2005).

The dilemma comes full circle when working with those people who have the least verbal communication skills. Walmsley and Johnson (2003:206) admit that for these people, an 'advocacy stance' within research is unlikely to be as they have defined, that is, properly inclusive. Whichever way one attempts to involve or engage - there is really no way of being sure that some people with learning difficulties want to be included and are getting something from the process. This is a problem signified by discussions on 'informed consent' in research, where difficulty is experienced, firstly, in knowing if an individual understands the researcher-researched relationship, and secondly, if that individual understands what it means to agree to take part (Concannon 2005, Stalker 1998). I certainly encountered this situation during the individual interviews I conducted, despite checking and rechecking that they wanted to take part. I recall one particular situation involving a young woman who, once we had completed our interview, took the picture we had created and wanted to show it to her key worker (her mentor). I suddenly panicked, realising that I obviously had not made it clear that I was going to keep the drawings and they were not for her to keep. Aware that I was in a relatively powerless position, I decided that if she insisted on keeping the drawing I could take a photocopy of it-which in the end was not necessary as she gave it back to me. A rather awkward situation was avoided, but I was left feeling a little uncomfortable. Who had the most power in this situation?

\section{Power and participation}

Of all the research participants with a learning disability, the most interesting and informative data came from a woman (whom I will refer to as Anne) in her midforties, whom I knew from the Gateway Club and who agreed to a life history interview. I specifically targeted this woman as we had become friends at the Club and I knew that she had good speech, lived independently, and showed an understanding of my being at university. Before we met for the interview I explained 
about my university course and my interest in friendships, and by her responses to me I was confident that she understood the project. Before our interview commenced I described the purpose of my project again and she expressed her willingness to take part. I was therefore confident that I had her informed consent and that the transaction between us was fair and balanced. She was able to read and write and so the use of the diagrams was very helpful to our discussions, and I felt she was happy to use the drawings as tools to help us discuss her friendships. I was very pleased with the results of this interview, and at the same time was moved by the difficulty she had faced in her life. I found myself becoming upset by certain events in her life that had taken her away from her home and friends. From the detail she gave, it was clear that any friendships she established as a child were severed when she was moved away and she had to create a completely new network of friends when she returned home. Prompted by my questions Anne created a timeline diagram, noting the dates of the significant moments in her life. There were a few gaps, but she was able to recall particular events like the institution she stayed in for over five years. What control did Anne have in the early part of her life?

In contrast to the Disabled Movement which has been fighting for empowerment and emancipation led by people with disabilities, the push towards participation for people with learning difficulties could be said to be orchestrated predominantly by the state, as part of a wider political strategy (Midgley 1986). It is widely conceived that as a significantly marginalised group, people with learning difficulties have been the victims of the increased power and control of the state in the twentieth century (see Arnstein's [1969] discussion of 'have-nots', which describes those people within society excluded from a political arena). Whereas the Disabled Movement has been able to engage in this political struggle on an academic level despite their relatively powerless position, people with learning difficulties have needed additional mechanisms and intervention, like advocacy, in order to be able to lever themselves into the political arena, due to communication constraints. In the push towards participation for adults with learning difficulties there remains an important question: have these changes ever intended to transfer power back to people with learning difficulties in order that they can control their affairs?

Studies of social policy discourse recognise that socially and financially disadvantaged and marginalised people are the least likely to be consulted or asked for their opinion (Midgley 1986). Midgley (1986:13) calls this a process whereby the 'poor and oppressed [are] mobilized by external agents', and dates the first contributions to this discourse back to the early 1970s. A similar critique is mirrored within participatory development and has arisen from criticism levelled at top-down development approaches (Cooke and Kothari 2001). A more participatory discourse, on the other hand, promotes the idea that the changes that happen or need to happen in people's lives are not decisions that should be made for people but should be made by people.

A useful model to illustrate the relationship between participation and empowerment is the ladder of citizen participation created by Arnstein (1969) (see Figure 2). For Arnstein (1969:217), 'each rung corresponds to the extent of citizens' power in determining the end product'. In this framework, power and participation are inextricably linked (Arnstein 1969, Smith and Jones 1981). Without real power to make change, Arnstein (1969:216) indicates that participation is an 'empty ritual'. There is acknowledgement that the process relies on 'wrestling' by the powerless, 
since 'those who have the power normally want to hang on to it' (Smith and Jones 1981:13).

Figure 2. Ladder of citizen participation

\begin{tabular}{|c|c|c|}
\hline 8. & Citizen control & \multirow{3}{*}{ Degrees of citizen power } \\
\hline 7. & Delegated power & \\
\hline 6 . & Partnership & \\
\hline 5 . & Placation & \multirow{3}{*}{ Degrees of tokenism } \\
\hline 4. & Consultation & \\
\hline 3. & Informing & \\
\hline 2. & Therapy & \multirow[b]{2}{*}{ Non-participation } \\
\hline 1. & Manipulation & \\
\hline
\end{tabular}

Source: Arnstein (1969)

Power is conceptualized in zero-sum terms where gaining power means taking it away from a more powerful group (a Weberian notion). Political power viewed in these fixed terms also represents a process of resistance and struggle (Craig and Mayo 1995). Craig and Mayo (1995:2) see 'effective participation as the key to the poor's struggle for equity, human rights and democracy'. The danger is, as James (1999:14) notes, that 'empowerment seems to have little more body to it than responsibility delegated from above', where a 'delegation' of power only serves to reinforce that no real power has been given. Eriksen (2001:159) asks: 'do people, when all is said and done, act under some form of coercion, or are they free to choose their own course of action? In a sense, both statements are correct. We choose our actions but not under circumstances of our own choice.'

Who is left making the final decision? It is only when user involvement moves from 'partnership' upwards that participation in this model is achieved. Participation is therefore only as effective as the processes set in place to ensure that power is invested. This framework does however make an assumption that every citizen has the same ability and rights to participate. Despite Arnstein's (1969) recognition of the position of 'have-nots' in North American society, there is perhaps a more fundamental barrier faced by people with learning difficulties. Not only does the language of participation assume the point at which people can participate from and to, it may also explain why those considered to have a limited 'capacity' cannot achieve real power.

In my experience, however, particularly through services like the Gateway Club and as a member of the local Mencap Society, levels of individual empowerment are gradually being achieved. After over 40 years of living at home with her parents, one of the people I have been working with at Gateway was given a supported flat in the town centre. This was the result of pressure on social services to provide accommodation for this individual who was living with very aged parents. Suddenly this person was now responsible for her own flat, housekeeping and cooking, and she was extremely happy. This supported living scheme is a rarity in the local area, but a 
powerful example of the levels of responsibility that some individuals are able to take on in order to have more control over their lives. Thinking back to Anne, her life has changed significantly since she was relocated back to the area she grew up in. She was given her own flat, with support once or twice a week for shopping and budgeting. She volunteers at a local voluntary organisation that provides support and information to people with learning difficulties. Anne is also responsible for running a self-advocacy project based in this organisation. What a fantastic example of empowerment arising from stepping up on the ladder of participation through partnership to delegated power.

\section{Participation as a form of control}

The 'pressure for participation' as described by Smith and Jones (1981) has been caused by the power differential between the governing and the governed. Despite the argument that participation has been introduced to avoid confrontation, it has been widely embraced not just by politicians but also by professionals within the disparate field of community and development work. Indeed it has now become so entrenched within practice that any attempt to criticise it has been treated with contempt (see Cooke and Kothari 2001 on 'political co-option'). Participation that is forced could be said to be a contradiction in terms. Surely to be denied choice is to be denied power. Henkel and Stirrat (2001:12-13, cited in Cooke and Kothari 2001) claim that 'the question that should be asked ... is not how much people are empowered, but for what?' Who benefits from participation? This concern is just as valid for the participation of adults with learning difficulties within their communities as it is in development work. Empowerment has been described as 'ambivalent' (Gledhill 1994), 'ambiguous' (Charlton 1998, James 1999), and as a 'buzz word' (Mullender and Ward 1991, Rowlands 1998) - the one thing that all authors seem to agree on is the difficulty in deciding what empowerment actually is and ultimately what defines the outcome of the process.

If power is viewed, as discussed earlier, in 'fixed terms', then it cannot be merely acquired or imagined, but will be passed or given from one person (or group of people) to another. Indeed the definition of empowerment reinforces this concept by the nature of power being 'bestowed' on someone (Rowlands 1998). This process is made more confusing when working with adults with learning difficulties, where Dowson (1997:105) suggests that 'those who are empowered may well find that the power has not been given but merely loaned, as in the gift of a parent who allows a teenager to exercise choice-but only if the parent judges that the choices are sensible'. Therefore, decision-making power is conditional, based on a judgement of whether that person can exercise their right to choose in certain circumstances. Hence participation is controlled, limited and not a reflection of autonomy. As Rowlands (1998:13) notes, unless empowerment is coupled with structural change in power relations, she considers it to be 'illusory'.

\section{Labelling-a help or a hindrance?}

I became friends with a young woman through the teenage drop-in sessions who had mild learning difficulties. Her speech and literacy were good and her social awareness excellent. In our discussions about friendships she made a very clear distinction between, in her words, 'special needs' and 'mainstream' people. When questioning 
her about her network linkage diagram she appeared frustrated by the limited opportunities to spend time in 'mainstream' social settings. Things like going to the pub were a rarity, and if she went she was normally taken by relatives or friends without learning difficulties of her age. She seemed to be striving to increase her social networks whilst at the same time recognising that she does have 'special needs' and therefore cannot necessarily have the 'normal' social life of a 20 year old.

The label 'learning difficulty' is just one of the categories used to describe a broad range of inherited and genetic disabilities referred to in the definitions section above. 'Learning disabilities', 'mental retardation' and 'special needs' are all words that have been, and in some cases still are, used to group together people with a huge range of needs and intervention requirements. Research into the labels used for adults with learning difficulties suggests that some people do not consider that they fit into a category at all, and may intentionally avoid the use of that label when engaged in dialogue about their needs (Finlay and Lyons 1998). In their article, Finlay and Lyons argue that the label of 'learning difficulty' can result in a negative impact on social identity, where achievement in a career, school or living independently is less likely. They term the process where decisions are made about the capabilities of those with a learning difficulty as 'negative social evaluation' (ibid:38).

There is an uncomfortable relationship between people who have learning difficulties and the label that they are ascribed. The tension arises from the way in which labels are used, both as a means of recognition and at the same time as a means of limiting and drawing boundaries around what people can achieve. A label therefore is a double-edged sword, which can be simultaneously used in defence in accessing services and support and will be used against an individual when they do not conform or may become resistant. It is a balancing act; if an individual becomes 'too' competent, the label may be withdrawn and services that work on behalf of adults with learning difficulties are faced with a bureaucratic dilemma (see discussion on 'theorising' in Walmsley and Johnson 2003:141).

Within development discourse, the practice of labelling is contested as a mechanism for homogenising the needs of those who find themselves categorised (e.g. the label of 'refugee', which creates a false sense that all those in that position have the same sort of group identity; Eyben and Moncrieffe 2006). Labelling is viewed as a 'construct', providing a convenient way of generalising the needs of a potentially diverse population. The process of labelling is also recognised as a means of maintaining existing power relations as part of the political discourse of development. There is clearly a purposive relationship between politics, decision-making and labelling of 'groups' of people. Again, there is agreement that the consequences of labels can be both empowering and disempowering. Effects like reductionism, stigmatisation and homogenisation are a reality in development situations, where 'power over' (VeneKlasen and Miller 2002) is the experience of those at the receiving end. Eyben and Moncrieffe (2006:4) call on development professionals to 'reflect on and respond to the political impact of labels' in order to ensure that the 'labels will support empowerment'. There appear to be some common themes here with the challenges that face those working with adults with learning difficulties. To what extent is it the 'fault of the label' that adults with learning difficulties are disempowered?

The label of 'learning difficulty' is inextricably linked to the prevailing medical discourse which has in effect defined what is healthy or normal as opposed to unhealthy or abnormal (Thompson 2003). As a consequence, the idea that people with 
a learning difficulty are 'mentally ill' is reinforced by the power invested in medical professionals to make decisions on behalf of those in need of additional care and support. This is critiqued by the social model of disability, which is based on research that has shown that the actions of others and societal barriers create disability-not individuals themselves (Boxall 2002). Hence disability is argued by some to be a social construction relevant to the dominant social and medical discourse identifying some people as different and less capable than an 'adult' (Walmsley and Downer, 1997). McIntosh (2002) argues that services for adults with learning difficulties operate in such a way as to offer empowerment with one hand, and then take it away with the other. He states that 'promotion of self-competence and promotion of selfdisablement are simultaneously encouraged by the apparatus of the state' (2002:75). In the case of my teenage friend, she is caught in the middle of this complex labelling process. She understands the distinction but feels held back by her status as 'special needs'. She constantly has to prove her competence in order to be a part of the coveted mainstream life that most of us take for granted.

\section{Steps in the 'right' direction}

There are examples of participatory techniques that have sought to address these issues and in particular to provide opportunities for adults with learning difficulties to initiate ideas and direct services. To this end, I will be focussing on four examples of practice aimed at empowering adults with learning difficulties through engaging them in the research process, making decisions about their support services, and case studies on examining integration within 'community life'. By way of setting the scene, I have developed a map (Figure 3) as a visual representation of the spheres of community engagement based on my own research and observations. The grey background denotes services for adults with a learning difficulty. Where circles overlap outside this area there is likely to be contact with mainstream activity. Arrows show relationships between services that are linked up to provide support and care.

It appears, albeit from a limited scope of research, that the confines of activities and services tailored towards those people with learning difficulties are difficult to break away from. This may either be because of the social and communication skills involved in engaging in a mainstream social network, or because of the assumptions made about the skills and ability of the person to adapt to different situations and people. Many of these concerns are of course valid and can often be dictated by the medical conditions associated with learning difficulties and genetic disorders. Nevertheless, this can create an environment where it is impossible for adults with learning difficulties to break away from these expectations and to participate on an equal level to achieve true empowerment. 
Figure 3. Community engagement: a visual representation

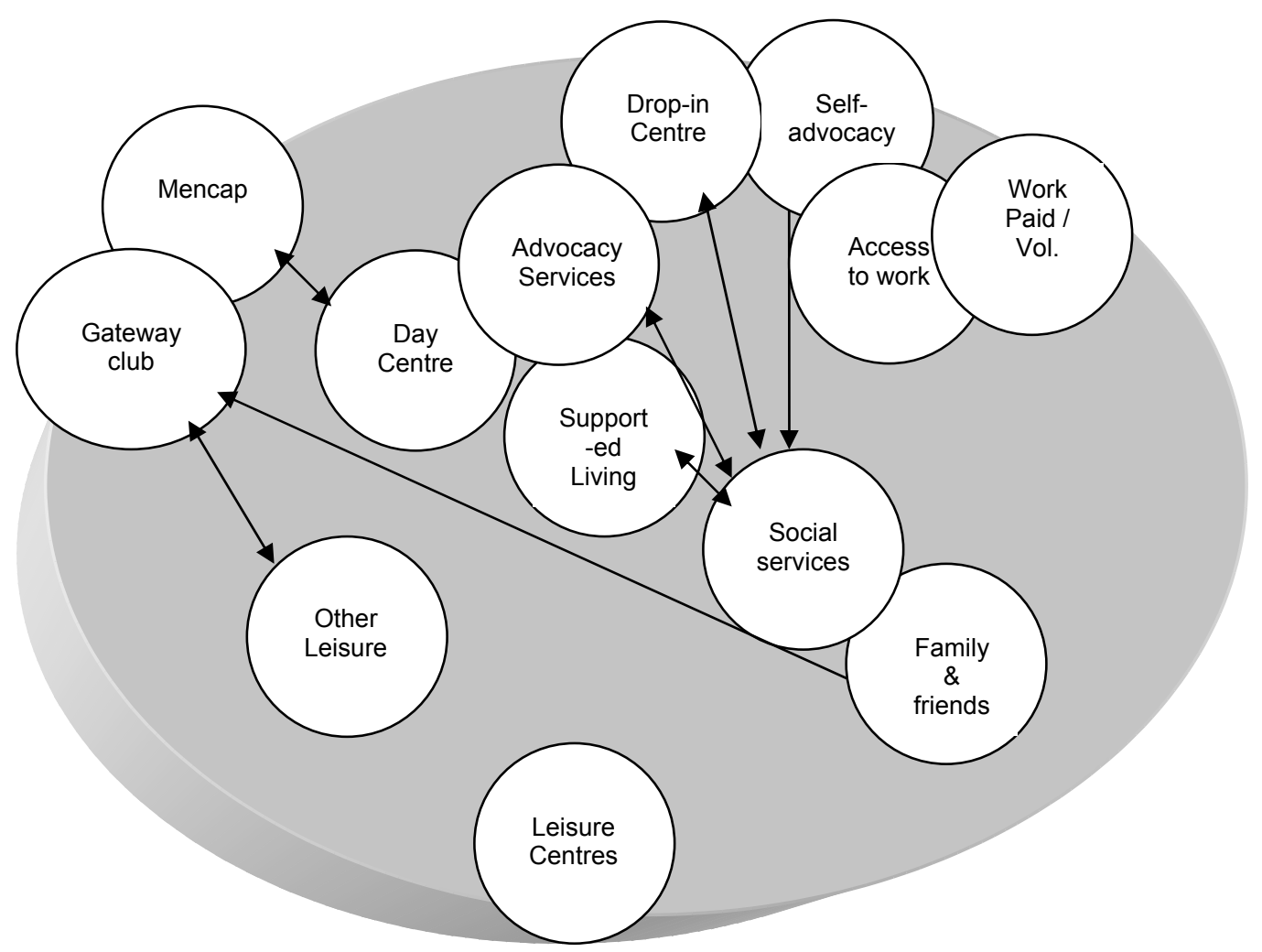

Communication channels do exist between the voluntary and statutory sector services, creating opportunities for feedback and consultation, and efforts are made through self-advocacy to not just be communicated 'to'. But unfortunately this will only have a positive impact on those able to communicate by some methods to an advocate or social worker. For those people with no intentional communication they must rely on families and friends around them to speak on their behalf.

In recognition of the power imbalance within existing research processes, there has been a movement towards 'emancipatory' or 'inclusive' research practices that seek to put the interests of people with disabilities at the forefront (Oliver 1996, Walmsley and Johnson 2003). This represents a paradigm shift within existing research practice whereby research is not done 'to' people with disabilities but 'with' people with disabilities. This change in the practice and structures of power within research resembles 'power with' (see VeneKlasen and Miller 2002) and notably involves empowerment and reciprocity (Oliver 1996). Walmsley and Johnson (2003:9) describe inclusive research as a process whereby 'people with learning disabilities are active participants, not only as subjects but also as initiators, doers, writers and disseminators of research'. Examples of life story research are particularly noteworthy, as individuals have sought out researchers to help create an historical record of their past. On rare occasions an 'account is written totally by the person with a learning disability' (ibid:131). By the authors' own admission, this level of participation in research has relied on 'articulate people with learning disabilities' (ibid:130). 


\section{Making choices}

In the UK Government's White Paper Valuing People (Department of Health 2001), four main aims were laid out: rights, independence, choice and inclusion. This paper includes recommendations to local authorities on the way in which they should continue to plan and provide services for people with learning disabilities. Most notably, the White Paper (ibid:51) states that 'services should respond to the wider aspirations of people with learning disabilities and give them more choice and control'. Of particular resonance regarding participation, the following warning is issued: 'it is no longer acceptable for organisations to view people with learning disabilities as passive recipients of services; they must instead be seen as active partners' (ibid:58). An example of a mechanism that has developed in response to this is the 'supported decision-making model'. It is a step forward from its predecessor, namely 'substitute decision-making', which allowed family members or professionals to make decisions on behalf of individuals deemed incompetent (particularly those with communication difficulties - see Concannon 2005:61-62).

Supported decision-making is based on the premise that 'all human beings communicate ... all human beings express choices and preferences about their lives ... [and] these choices and preferences are the building blocks of decisions' (URL 3). In research conducted on how decision-making can be supported and demonstrated, it was concluded that 'some people with learning difficulties and high support needs received good support to make choices and be in control of their own lives' (Concannon 2005:61-62). Concannon goes on to note that capacity becomes an irrelevant concept when this approach is adopted. Allowing for choice and control, whilst providing intensive personalised support to adults with learning difficulties, is explored by case studies in Ramcharan and Grant (2005).

\section{Why isn't participation working?}

A Task Force was set up to report on the progress of the aims of the White Paper Valuing People, and a report from 2004 stated some very positive outcomes about the level of involvement that people had in their own services, particularly highlighting a 'person-centred approach' (Learning Disability Task Force 2004). However, the latest report from the Task Force is entitled Could Do Better, and the headline information indicates that there are significant failings in relation to the aims of Valuing People, and the authors are saddened to conclude that 'we all know that people with learning disabilities continue to be treated unequally by society' (Learning Disability Task Force 2007:5). One explanation, building on previous work by Grant (1997), is the apparent tension arising from two competing discourses on participation. One discourse is held by politicians, policy-makers and service providers, who aim to find ways to involve users in the services that are provided for them and encourage representation in consultative forums. Running parallel is the service user discourse, which is concerned with 'their lives, rights, choices and opportunities' (ibid:122). The politicians led by social policy development aims want to involve, and the service users themselves want to experience some form of empowerment and autonomy in their lives (also discussed in Mullender and Ward 1991).

Stevenson and Parsloe (1993) also highlight concerns with the lack of enforcement of the rights of people with learning difficulties, and a concern that service users are often at the mercy of professional judgement and budget constraints. They critique the 
ways in which an 'assessment of need' takes power away, and give an example where an individual with communication difficulties did not have her preferences taken into account. The intention in social policy is clear-individuals have the right to be part of the decisions around an assessment of their need and intervention. But in reality the relationship between perceived risk, autonomy and protection sets a precedent for an imbalance of power between the service user and the professional, justified through a 'duty of care' (Stevenson and Parsloe 1993).

\section{Protection or prevention}

Judgements based on ethical duties can lead to the withdrawal of autonomy experienced by adults with learning difficulties, resulting in what Stevenson and Parsloe (1993:15) argue is a 'rhetoric of self-determination'. This is reflected by the notion of 'partnership' between a worker and a service user, where a process of 'negotiation' is intended to encourage involvement and participation in decisionmaking. Evidence suggests that these 'negotiations' are more about influence and persuasion rather than 'acceptance of the client's wishes and needs at their face value' (ibid:21). A lead professional or worker is accountable for decisions made on behalf of a client, and it follows that issues of risk and safeguarding welfare are of the uppermost importance. Given the nature of local authority accountability towards adults with learning difficulties, is this level of care beyond scrutiny? Whereas there is clear precedent for a duty to protect, it does appear that there is no duty to empower.

Levels of involvement can also be dependent on the attitudes of family members to engaging with consultative processes in the allocation of service provision. Grant's (1997:125-140) analysis of the Welsh strategy contributes insights into the level at which service users and in particular their carers and families not only wanted to get involved but understood that they had a right to be involved. Grant explains there were mixed reactions and expectations from families, and it became apparent that the willingness of the families to engage often dictated the involvement of the end service user. A greater user involvement, however, is only one step towards empowerment of adults with learning difficulties. Whilst Grant has suggested ways in which this consultation method is working, weaknesses are reflected in the extent of involvement of parents and families, and also through the inescapable reliance on the judgements of support workers and local authority assessments. User involvement has to be brokered by key workers or lead care professionals particularly in order for those with severe communication difficulties to be involved. Clearly this represents a level of transferring decision-making power, though whether it could be called true empowerment through participation in the context I have described is still uncertain.

\section{Conclusion}

Participatory discourse offers degrees of opportunity for adults with learning difficulties to engage. However, without significant changes to beliefs in autonomous thought and action by those in positions of power, it appears an empty promise In development discourse, the attempts to empower are based on a belief that the use of the right tools and techniques can allow a minority voice to be heard and understood. By contrast, the structural barriers faced by those 'labelled' with a learning difficulty prevail and dominate any opportunities to engage. Whilst the concerns associated with the ethical duty of care are clearly important and critical in protecting the rights of 
adults with learning difficulties, they suffocate potential and reinforce the position of 'eternal child' (Aspis 1997). A participatory stance has, as Ramcharan et al. (1997:253) suggest, 'a contribution to make in alleviating some of the effects of oppression, inequality and exclusion'. In order to move forward, there needs to be a much larger investment in technology and systems that can help people with communication difficulties to be heard and understood. This would also involve a process of skilling up professionals who work alongside people with learning difficulties, so as to adapt participatory methods in order to create a meaningful dialogue. The steps towards empowerment may be small, but with every effort made towards ensuring that the rights of people with learning difficulties are considered, several small steps will make a difference in the long term. We must ensure that power does not remain a political instrument of control, but rather is invested and shared to counter a long history of disempowering experiences for people with learning difficulties.

\section{References}

Arnstein, S. 1969. Ladder of citizenship participation. Journal of the American Institute or Planners 35, 216-224.

Aspis, S. 1997. Self-advocacy for people with learning difficulties: does it have a future? Disability \& Society 12, 647-654.

Boxall, K. 2002. Individual and social models of disability and the experiences of people with learning difficulties. In Learning Disability: A Social Approach (ed.) D.G. Race, 209-226. London: Routledge.

Brandon, D. with A. Brandon and T. Brandon. 1995. Advocacy: Power to People with Disabilities. Birmingham: Venture Press.

Charlton, J. 1998. Nothing About Us Without Us. Berkeley: University of California Press.

Cogher, L. 2005. Communication and people with learning disabilities. In Learning Disability: A Life Cycle Approach to Valuing People (eds.) G. Grant, P. Goward, M. Richardson and P. Ramcharan, 260-284. Berkshire: Open University Press.

Cooke, B. and U. Kothari (eds). 2001. Participation: The New Tyranny? London: Zed Books.

Concannon, L. 2005. Planning for Life: Involving Adults with Learning Disabilities in Service Planning. Oxon: Routledge.

Craig, G. and M. Mayo (eds). 1995. Community Empowerment. London: Zed Books.

Department of Health. 2001. Valuing People. London: Department of Health.

Eriksen, T. H. 2001. Small Places, Large Issues. London: Pluto Press.

Eyben, R. and J. Moncrieffe. 2006. The power of labelling in development practice. IDS Policy Briefing 28 (http://www.ids.ac.uk/ids/bookshop/briefs/PB28.pdf).

Finlay, M. and E. Lyons. 1998. Social identity and people with learning difficulties: implications for self-advocacy groups. Disability \& Society 13, 37-51. 
Gledhill, J. 1994. Power and its Disguises: Anthropological Perspectives on Politics. London: Pluto Press.

Grant, G. 1997. Consulting to involve or consulting to empower? In Empowerment in Everyday Life (eds) P. Ramcharan, G. Roberts, G. Grant and J. Borland London: Jessica Kingsley Publishers.

Grant, G., P. Goward, M. Richardson and P. Ramcharan (eds). 2005. Learning Disability: A Life Cycle Approach to Valuing People. Berskhire: Open University Press.

Gray, B. and G. Ridden. 1999. Lifemaps of People with Learning Disabilities. London: Jessica Kingsley Publishers.

James, W. 1999. Empowering ambiguities. In The Anthropology of Power (ed.) A. Cheater, 13-27. London: Routledge.

Learning Disability Task Force. 2004. Annual Report 2004: Challenging, Listening, Helping to Improve Lives. London: Department of Health. Available at http://www.dh.gov.uk/en/Publicationsandstatistics/Publications/AnnualReport s/DH 4112550

2007. Valuing People: Task Force Annual Report on Learning Disability, 2007. London: Department of Health. Available at http://www.valuingpeople.gov.uk/dynamic/valuingpeople7.jsp

McIntosh, P. 2002. An archi-texture of learning disability services: the use of Michel Foucault. Disability \& Society 17, 65-79.

Midgley, J. 1986. Community Participation, Social Development and the State. London: Methuen.

Mullender, A. and D. Ward. 1991. Self-Directed Groupwork: Users Take Action for Empowerment. London: Whiting \& Birch.

Oliver, M. 1996. Understanding Disability. London: Macmillan.

Ramcharan, P. and G. Grant. 2005. Making a life in the community. In Learning Disability: A Life Cycle Approach to Valuing People (eds) G. Grant, P. Goward, M. Richardson and P. Ramcharan, 604-619. Berkshire: Open University Press.

Ramcharan, P., G. Roberts, G. Grant and J. Borland (eds). 1997. Empowerment in Everyday Life. London: Jessica Kingsley Publishers.

Roberts, G. 1997. Empowerment and community care: some of the legal issues. In Empowerment in Everyday Life (eds) P. Ramcharan, G. Roberts, G. Grant and J. Borland, 157-171. London: Jessica Kingsley Publishers.

Rooney, S. 2002. Social inclusion and people with profound and multiple disabilities: myth or reality? In Learning Disability: A Social Approach (ed.) D.G. Race, 154-170. London: Routledge.

Rowlands, J. 1998. A word of the times, but what does it mean? Empowerment and practice of discourse development. In Women and Empowerment: Illustrations from the Third World (ed.) H. Afshar, 11-32. New York: St. Martin's Press.

Smith, L. and D. Jones. 1981. Deprivation, Participation and Community Action, London: Routledge \& Kegan Paul. 
Stalker, K. 1998. Some ethical and methodological issues in research with people with learning difficulties. Disability \& Society 13, 5-19.

Stevenson, O. and P. Parsloe. 1993. Community Care and Empowerment. York: Joseph Rowntree Foundation.

Thomforde, D. 1998. Using participative techniques with people with disabilities. In PLA Notes 32, 126-129.

Thompson, S. A. 2003. Subversive political praxis: supporting choice, power and control for people with learning difficulties. Disability \& Society 18, 719-736.

VeneKlasen, L. and V. Miller. 2002. Power and empowerment. PLA Notes 43, 39-41.

Walmsley, J. and J. Downer. 1997. Shouting the loudest: self-advocacy, power and diversity. In Empowerment in Everyday Life (eds) P. Ramcharan, G. Roberts, G. Grant and J. Borland, 35-47. London: Jessica Kingsley Publishers.

Walmsley, J. and K. Johnson. 2003. Inclusive Research with People with Learning Disabilities. London: Jessica Kingley Publishers.

\section{Websites}

URL 1. Mencap: What is learning disability? http://www.mencap.org.uk/html/about learning disability/what is lea rning disability.asp

URL 2. Mencap: Common causes of learning disability http://www.mencap.org.uk/html/about_learning_disability/learning disability common.asp

URL 3. Joseph Rowntree Foundation: Demonstrating control of decisions by adults with learning difficulties who have high support needs, 2001. http://www.jrf.org.uk/knowledge/findings/socialcare/021.asp

\section{About the author}

Beccy Blow graduated from Goldsmiths College in 2006 after completing an MA in Anthropology in Community and Youth Work. She is now a full-time Youth Worker based in West Sussex, UK, working for the statutory authority. Beccy has continued to maintain an interest in working with people with learning difficulties and in particular is looking to ensure that young people with learning difficulties are included in the youth offer provided by the local authority. Her interests include music, leisure, sports and creative crafts. She can be reached at beccy.blow@westsussex.gov.uk 